\title{
Crystal Structures and Properties of a Monoprotonated Porphyrin
}

\author{
Tatsuhiko Honda, ${ }^{a}$ Takahiko Kojima* ${ }^{\text {b }}$ and Shunichi Fukuzumi*a \\ Received (in $X X X, X X X)$ Xth $X X X X X X X X X 200 X$, Accepted Xth XXXXXXXXX 200X \\ First published on the web Xth $X X X X X X X X X 200 X$ \\ ${ }_{5}$ DOI: 10.1039/b000000x
}

\begin{abstract}
A stable monoprotonated porphyrin (porphyrin monoacid) was obtained by reaction of saddle-distorted dodecaphenylporphyrin with anthracene sulfonic acids and crystal structures of its supramolecular assemblies were determined.
\end{abstract}

${ }_{10}$ Porphyrins are dibasic heteroaromatic compounds to accept two protons to be diprotonated species called as porphyrin diacids. ${ }^{1} \quad$ The protonation of porphyrins have been investigated for a long time due to its alteration of structures and characteristics of porphyrins. ${ }^{2}$ In the case of meso15 substituted porphyrins, the one-step diprotonation occurs simultaneously to give diprotonated species without any detectable intermediates. ${ }^{1,3}$ In particular, saddle-distorted dodecaphenyl-porphyrin $\left(\mathrm{H}_{2} \mathrm{DPP}\right)^{4}$ facilitates its protonation by the out-of-plane orientation of the lone pairs of its pyrroles 20 The diprotonated species $\left(\mathrm{H}_{4} \mathrm{DPP}^{2+}\right)$ are stabilized by its intrinsic conformational distortion derived from intramolecular steric hindrance among peripheral phenyl groups, $^{5}$ and also by forming hydrogen bonding with anionic species, which are conjugate bases of $\mathrm{Br} \phi$ nstead acids, to give 25 a supramolecular assembly. ${ }^{6}$

So far, many attempts have been made to detect and isolate porphyrin monoacids, which are monoprotonated species of porphyrins as intermediates in the course of the diprotonation, by protonation of porphyrins with $\mathrm{Br} \phi$ nstead $\mathrm{acid}^{7}$ or 30 deprotonation of corresponding diacids by dilution ${ }^{8}$ or addition of base. $^{9} \quad$ Although the crystal structure determination of porphyrin monoacid has been made on $\beta$ substituted octaethylporphyrinium $\left(\mathrm{H}_{3} \mathrm{OEP}^{+}\right),{ }^{8 \mathrm{~b}, 10}$ to date, no crystal structure determination has been made on porphyrin 35 monoacids having substituents at the meso positions. Thus, porphyrin monoacids have been "missing species" for the meso-substituted porphyrins. The arguments on porphyrin monoacids have been limited to their formation and protonation equilibrium, and their characteristics have not ${ }_{40}$ been discussed due to the difficulty of their isolation and stabilization to achieve thorough characterization.

We report herein for the first time the formation and crystal structure determination of supramolecular assemblies involving a porphyrin monoacid, $\mathrm{H}_{3} \mathrm{DPP}^{+}$, and sulfonate 45 anions that exhibit hydrogen-bonding ability due to the delocalization of negative charge on the three oxygen atoms. We also report the spectroscopic and electrochemical properties of the saddle-distorted porphyrin monoacid. Monoprotonation of $\mathrm{H}_{2} \mathrm{DPP}$ provides a new way not only to 50 control the electronic and redox porperties of porphyrins but also to construct supramolecular assemblies.

As shown in Scheme $1, \mathrm{H}_{2} \mathrm{DPP}$ can undergo two-step protonation equilibrium to give $\mathrm{H}_{3} \mathrm{DPP}^{+}$and $\mathrm{H}_{4} \mathrm{DPP}^{2+}$ as pro-

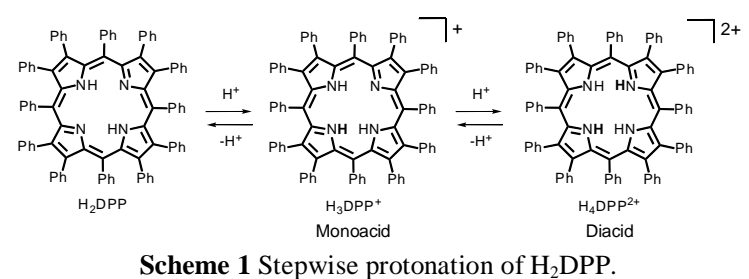

ducts of monoprotonation and diprotonation, respectively. We examined the reaction of $\mathrm{H}_{2}$ DPP and excess amount of anthracene sulfonic acid derivatives ${ }^{11}$ to obtain porphyrin monoacid salts of $\mathrm{H}_{2}$ DPP having sulfonates as counter anions. ${ }_{60}$ In the case of 2-anthracene sulfonic acid $\left(2-\mathrm{AN}_{-} \mathrm{SO}_{3} \mathrm{H}\right),{ }^{12}$ a green single crystal of $\left[\mathrm{H}_{3} \mathrm{DPP}\right]\left(2-\mathrm{AN}_{-} \mathrm{SO}_{3}\right) \cdot \mathrm{CH}_{3} \mathrm{OH}$ (1) was obtained by two-layered recrystallization with addition of $\mathrm{CH}_{3} \mathrm{OH}$ on the top of the toluene solution of $\mathbf{1}$. As for 2,6anthracene disulfonic acid $\left(2,6-\mathrm{AN}-\left(\mathrm{SO}_{3} \mathrm{H}\right)_{2}\right){ }^{12}$ the diacid 65 reacted with the two molecules of $\mathrm{H}_{2} \mathrm{DPP}$ to give a 2:1 salt, $\left[\mathrm{H}_{3} \mathrm{DPP}\right]_{2}\left(2,6-\mathrm{AN}-\left(\mathrm{SO}_{3}\right)_{2}\right) \cdot\left(\mathrm{CH}_{3} \mathrm{OH}\right)_{2}$ (2), which was obtained as green crystals by two-layered recrystallization with addition of $\mathrm{CH}_{3} \mathrm{OH}$ on the top of the $\mathrm{CH}_{2} \mathrm{Cl}_{2}$ solution of 2 . The selective crystallization of $\mathbf{1}$ and $\mathbf{2}$ should be ascribed to 70 the better crystallinity of the monoacid salts than that of the corresponding diacid salts and that causes equilibrium shift to afford the monoacid salts, as described in Scheme 1.

The crystal structure of $\mathbf{1}$ is shown in Fig. 1(a). $\neq$ In this compound, the saddle-distorted $\mathrm{H}_{3} \mathrm{DPP}^{+}$forms hydrogen 75 bonding among two of $\mathrm{N}-\mathrm{H}$ protons of pyrroles and two of oxygen atoms in the sulfonate group of the 2- $\mathrm{AN}-\mathrm{SO}_{3}{ }^{-}$anion in the interatomic distances of 2.867(7) and 2.89(1) $\AA$ (see ESI Fig. S1(a)). $\dagger$ On the other side, a methanol molecule is hydrogen-bonded asymmetrically, showing interatomic 80 distances of 2.911(5) and 2.862(6) A (see ESI Fig. S1(a)). $\dagger$ The anthracene moiety was settled in a cleft formed by the two phenyl groups attached to a pyrrole tilted up toward the anthracene part, forming $\pi-\pi$ interaction with the phenyl (a)

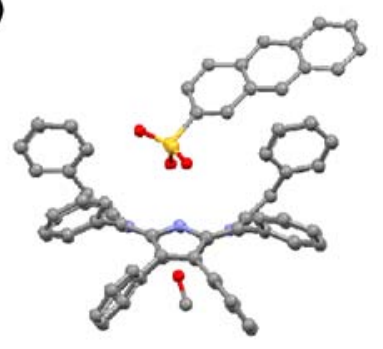

(b)

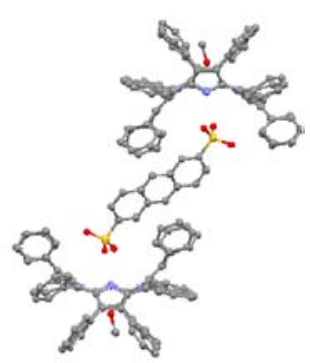

85 Fig. 1 Crystal structures of 1 (a) and 2 (b). Gray carbon, blue nitrogen, red oxygen, yellow sulfur. Hydrogen atoms and solvent molecules of crystallization are omitted for clarity. 
groups (see ESI Fig. S2(a)). $\dagger$

In the crystal of 2 , the two $\mathrm{H}_{3} \mathrm{DPP}^{+}$units are linked by the 2,6-AN- $\left(\mathrm{SO}_{3}{ }^{-}\right)_{2}$ dianion as shown in Fig. 1(b). $\neq$ Both of the sulfonate groups in 2,6- $\mathrm{AN}-\left(\mathrm{SO}_{3}{ }^{-}\right)_{2}$ bind to the $\mathrm{N}-\mathrm{H}$ protons 5 of pyrroles of $\mathrm{H}_{3} \mathrm{DPP}^{+}$with hydrogen bonding in the distances of 2.733(4) and 2.853(4) $\AA$ (see ESI Fig. S1(b)). $\dagger$ For the two $\mathrm{H}_{3} \mathrm{DPP}^{+}$moieties, the oxygen atom in the $\mathrm{CH}_{3} \mathrm{OH}$ molecule is bound to the two of pyrrole nitrogen atoms in $\mathrm{H}_{3} \mathrm{DPP}^{+}$via hydrogen bonding in the distances of 2.844(6) and 2.860(4) $\AA$ 10 (see ESI Fig. S1(b)). $\dagger$ As well as in the case of 1, the anthracene moiety was placed in the cleft of the two phenyl groups in each $\mathrm{H}_{3} \mathrm{DPP}^{+}$(see ESI Fig. S2(b)). $\dagger$

As a comparison, we also conducted the reaction of $\mathrm{H}_{2} \mathrm{DPP}$ with 2-anthracene carboxylic acid (2-AN-COOH). ${ }^{11}$ A green 15 single crystal of the diacid salt, $\left[\mathrm{H}_{4} \mathrm{DPP}\right](2-\mathrm{AN}-\mathrm{COO})_{2}$ (3), was obtained by the same method as that for $\mathbf{1}$ (see ESI Fig. S3). $\dagger \ddagger$ Each 2-AN-COO ${ }^{-}$anion binds to the $\mathrm{H}_{4} \mathrm{DPP}^{2+}$ dication via two-point hydrogen bonding in the distances of 2.637(4) and 2.688(3) $\AA$ from one side and 2.725(4) and 2.660(3) $\AA$ 20 from the other side of the porphyrin plane (ESI Fig. S1(c)), $\dagger$ respectively, as observed in $\left[\mathrm{H}_{4} \mathrm{DPP}\right][\mathrm{Zn}(\mathrm{OPPc})$ (4-pyridinecarboxylate $)]_{2}\left(\mathrm{H}_{2} \mathrm{OPPc}=\right.$ octaphenylphtahlocyanine $){ }^{6}$

The displacement of each atom from the least-squares mean plane of 24 atoms of the porphyrin cores in $\mathbf{1}$ - $\mathbf{3}$ indicated 25 saddle distortion and the extent of distortion of $\mathrm{H}_{3} \mathrm{DPP}^{+}$was comparable to that of $\mathrm{H}_{4} \mathrm{DPP}^{2+}$ (see ESI Fig. S4). $\dagger$.

The titration of $\mathrm{H}_{2}$ DPP by 2-anthracene sulfonic acid (2$\left.\mathrm{AN}-\mathrm{SO}_{3} \mathrm{H}\right)$ in benzonitrile (PhCN) allowed us to observe clearly distinguishable two-step spectral changes as shown in ${ }_{30}$ Fig. 2(a) with showing isosbestic points in each step. The equilibrium constants of the two-step protonation of $\mathrm{H}_{2} \mathrm{DPP}$ by $2-\mathrm{AN}-\mathrm{SO}_{3} \mathrm{H}$ were determined to be $K_{1}=8.1 \times 10^{5} \mathrm{~mol}^{-1}$ $\mathrm{dm}^{3}$ and $K_{2}=4.2 \times 10^{5} \mathrm{~mol}^{-1} \mathrm{dm}^{3}$, respectively. ${ }^{13}$ As can be seen in the inset of Fig. 2(a), the absorbance change at $470 \mathrm{~nm}$

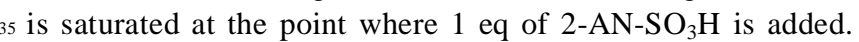
This clearly indicates the formation of $\mathrm{H}_{3} \mathrm{DPP}^{+}$in solution. ${ }^{14}$ The same spectrum was observed for the solution of the single crystals of $\mathbf{1}$ in $\mathrm{PhCN}$, indicating that the monoacid is stable in solution in the presence of the sulfonate anion (see ESI Fig. $\left.{ }_{40} \mathrm{~S} 5(\mathrm{a})\right) . \dagger$ In addition, the spectrum of the single crystals of 2 also showed the same spectrum as that of $\mathbf{1}$ (see ESI Fig. S5(b)). $\dagger$ In sharp contrast, one-step spectral change observed in the course of the titration with 2-AN-COOH, with showing isosbestic points, as shown in Fig. 2(b). The equilibrium 45 constant for 2 -AN-COOH was determined to be $3.8 \times 10^{11}$ $\mathrm{mol}^{-2} \mathrm{dm}^{6} .^{13}$ In the case of 2-AN-COOH, the addition of 2 eq of the acid is required to observe the saturation of absorption change as depicted in the inset of Fig. 2(b), indicating that the simultaneous diprotonation occurs.

50 On the contrary, in dimethyl sulfoxide (DMSO), the titration of $\mathrm{H}_{2} \mathrm{DPP}$ by 2-AN-SO $\mathrm{S}_{3} \mathrm{H}$ showed only one-step spectral change, which was assignable to monoprotonation and the equilibrium constant of this process was determined to be $1.4 \times 10^{3} \mathrm{~mol}^{-1} \mathrm{dm}^{3}$. The addition of $2-\mathrm{AN}-\mathrm{COOH}$ into the ${ }_{55}$ DMSO solution of $\mathrm{H}_{2} \mathrm{DPP}$ gave rise to one-step spectral change and the equilibrium constant was determined to be $6.2 \times 10^{6} \mathrm{~mol}^{-2} \mathrm{dm}^{6}$. In comparison with spectral change observed in PhCN, we assigned the spectrum obtained in the
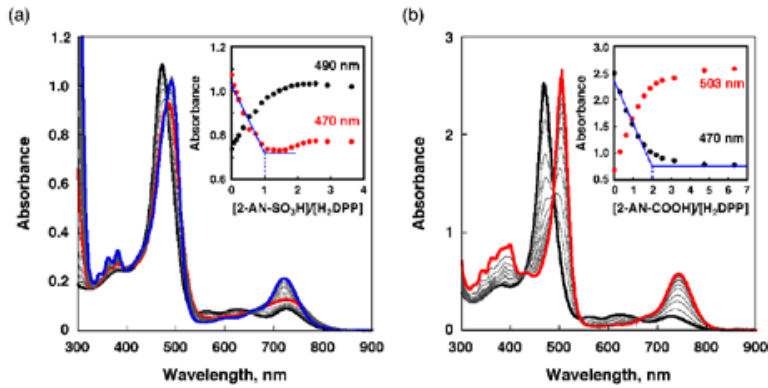

60 Fig. 2 Absorption spectral change in the course of titration of $\mathrm{H}_{2} \mathrm{DPP}$ with 2-AN- $\mathrm{SO}_{3} \mathrm{H}$ and 2-AN-COOH in PhCN at room temperature: (a) 0 - 4 eq of 2-AN- $\mathrm{SO}_{3} \mathrm{H}$ (inset: absorbance change at $470 \mathrm{~nm}$ (red) and $490 \mathrm{~nm}$ (black)) and (b) 2-AN-COOH (inset: absorbance change at $503 \mathrm{~nm}$ (red) and $470 \mathrm{~nm}$ (black)). The concentration of $\mathrm{H}_{2} \mathrm{DPP}$ were $6.7 \times 10^{-6} \mathrm{~mol}$ $65 \mathrm{dm}^{-3}$ for $2-\mathrm{AN}-\mathrm{SO}_{3} \mathrm{H}$ and $1.7 \times 10^{-5} \mathrm{~mol} \mathrm{dm}^{-3}$ for $2-\mathrm{AN}-\mathrm{COOH}$.

reaction of $\mathrm{H}_{2} \mathrm{DPP}$ with 2-AN-SO $\mathrm{S}_{3} \mathrm{H}$ to that of $\mathrm{H}_{3} \mathrm{DPP}^{+}$and that for the reaction of $\mathrm{H}_{2} \mathrm{DPP}$ with 2-AN-COOH to $\mathrm{H}_{4} \mathrm{DPP}^{2+}$, although the absorption maxima were not the same as those in $\mathrm{PhCN}$ (see ESI Fig. S6). $\dagger$ In DMSO, the solvent molecule is 70 expected to bind strongly to the pyrrole $\mathrm{N}-\mathrm{H}$ with hydrogen bonding and to inhibit the hydrogen binding of the weak conjugate base. ${ }^{1} \mathrm{H}$ NMR spectra in the course of the titration with 2-AN-COOH in DMSO- $d_{6}$ exhibited line-broadening, probably due to the restriction of molecular motion by 75 hydrogen bond formation of the stronger conjugate base, 2$\mathrm{AN}-\mathrm{COO}^{-}$, with $\mathrm{H}_{4} \mathrm{DPP}^{2+}$ formed (see ESI Fig. S7). $\dagger$ In sharp contrast, ${ }^{1} \mathrm{H}$ NMR spectra for the titration with $2-\mathrm{AN}-\mathrm{SO}_{3} \mathrm{H}$ showed no line-broadening and no change in chemical shifts of its signals, indicating no hydrogen bond formation.

80 The fluorescence spectrum of $\mathbf{1}$ was measured in $\mathrm{PhCN}$ with photoexcitation at $450 \mathrm{~nm}$ to exhibit the emission maximum at $796 \mathrm{~nm}(\phi=0.033)$ with $1 \mathrm{eq}$ of $2-\mathrm{AN}_{-} \mathrm{SO}_{3} \mathrm{H}$ and $786 \mathrm{~nm}(\phi=0.058)$ with 2 eq of $2-\mathrm{AN}_{-} \mathrm{SO}_{3} \mathrm{H}$, which were blue-shifted in comparison with that of $\mathrm{H}_{2} \mathrm{DPP}$ (810 nm, $\phi=$ ${ }_{85} 0.006$ ) and in much higher quantum yields (see ESI Fig. S8). $\dagger$ The fluorescence spectrum of $\mathbf{3}$ was also obtained under the same conditions to exhibit the emission maximum at $808 \mathrm{~nm}$ ( $\phi=0.011$ ) with 2 eq of $2-\mathrm{AN}-\mathrm{COOH}$, which was only slightly blue-shifted form that of $\mathrm{H}_{2} \mathrm{DPP}$.

90 The redox behavior of $\mathrm{H}_{3} \mathrm{DPP}^{+}$was irreversible in cyclic voltammograms in $\mathrm{PhCN}$ and DMSO. Therefore, by measuring differential pulse voltammograms (DPV) of $\mathrm{H}_{2} \mathrm{DPP}$ with the addition of $2-\mathrm{AN}-\mathrm{SO}_{3} \mathrm{H}$ in $\mathrm{PhCN}(0.1 \mathrm{M}[(n-$ butyl $\left.)_{4} \mathrm{~N}\right] \mathrm{PF}_{6}$ as an electrolyte), we could observe a new peak 95 at $-0.70 \mathrm{~V}$ relative to SCE as $0 \mathrm{~V}$ up to the addition of 1 eq of 2-AN-SO $\mathrm{S}_{3} \mathrm{H}$ (see ESI Fig. S10). $\dagger^{15}$ The potential was higher than that of $\mathrm{H}_{2} \mathrm{DPP}(-1.20 \mathrm{~V})$ and lower than that of $\mathrm{H}_{4} \mathrm{DPP}^{2+}$ $(-0.45 \mathrm{~V})$. This also lends credence to the formation of $\mathrm{H}_{3} \mathrm{DPP}^{+}$. In DMSO in the presence of $0.1 \mathrm{M}$ of $[(n-$ 100 butyl $\left.{ }_{4} \mathrm{~N}\right] \mathrm{PF}_{6}$ as an electrolyte, we could observe only one peak at $-0.85 \mathrm{~V}$ by the addition of $2-\mathrm{AN}-\mathrm{SO}_{3} \mathrm{H}$ and $-0.76 \mathrm{~V}$ by the addition of 2-AN-COOH, exhibiting anodic shift compared to that of $\mathrm{H}_{2} \mathrm{DPP}$ in DMSO $(-1.26 \mathrm{~V})$.

Finally, we considered the effect of hydrogen bonding 105 between protonated species of $\mathrm{H}_{2} \mathrm{DPP}$ and conjugate base of acid employed. As described above, an acid involving strongly hydrogen-bonding conjugate base such as carboxylic acids gives rise to diprotonation, while an acid involving 
a)

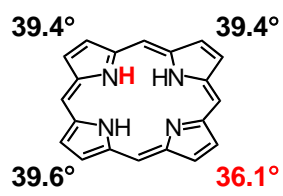

b)



Fig. 3 Schematic description of DFT-optimized structures of $\mathrm{H}_{3} \mathrm{DPP}^{+}$(a) and that hydrogen-bonded with 2-AN-COO ${ }^{-}$(b). Values described in the figure are dihedral angles relative to each porphyrin mean plane. The 5 phenyl groups of $\mathrm{H}_{3} \mathrm{DPP}^{+}$are omitted for clarity. $\mathrm{R}$ in (b) stands the 2anthryl moiety.

poorly hydrogen-bonding conjugate base such as sulfonic acids affords step-wise protonation to provide the monoacid. We conducted DFT calculations on $\mathrm{H}_{3} \mathrm{DPP}^{+}$and that hydro10 gen-bonded with 2-AN-COO ${ }^{-}$at the B3LYP/6-31G level of theory. ${ }^{16}$ As for the porphyrin monoacid, the dihedral angles of pyrroles relative to the $\mathrm{H}_{3} \mathrm{DPP}^{+}$mean plane were estimated as shown in Fig. 3(a). The non-protonated pyrrole showed the dihedral angle of $36.1^{\circ}$. On the other hand, the hydrogen15 bonded monoacid exhibited the dihedral angles as demonstrated in Fig. 3(b) and a larger dihedral angle $\left(44.9^{\circ}\right)$ was obtained for the non-protonated pyrrole. This result suggests that the non-protonated pyrrole in the hydrogenbonded porphyrin monoacid is more subject to be protonated 20 than the counterpart. Thus, the second protonation should be enhanced to give the corresponding diacid.

In summary, we succeeded in the isolation and crystal structure determination of a meso-substituted porphyrin monoacid derivative with saddle distortion by controlling ${ }_{25}$ hydrogen-bonding ability of conjugate base of the $\mathrm{Br} \phi$ nstead acid used for protonation. Weakly hydrogen-bonding conjugate base such as sulfonates gave the porphyrin monoacid in the crystal as well as in solution, however, strongly hydrogen-bonding conjugate base such as 30 carboxylates afforded the porphyrin diacid. The sulfonate anions are not interacting in solution with the monoacid, however, they can form two-point hydrogen bonding with the $\mathrm{N}-\mathrm{H}$ protons of pyrroles in the saddle distorted monoacid in the crystal. The intrinsic saddle distortion of $\mathrm{H}_{2} \mathrm{DPP}$ may 35 contribute to the stabilization of the porphyrin monoacid, allowing us to reveal its characteristics. The results reported herein will provide clear and precise description of a "missing species" in porphyrin chemistry and a new standpoint to develop novel supramolecular assemblies based on porphyrin 40 monoacids.

\section{Notes and references}

${ }^{a}$ Department of Material and Life Science, Osaka University and SORST (JST), 2-1 Yamada-oka, Suita, Osaka 565-0871, Japan. Fax: +81-6-68797370; E-mail: fukuzumi@chem.eng.osaka-u.ac.jp

${ }_{45}{ }^{b}$ Department of Chemistry, University of Tsukuba, 1-1-1 Tennoudai,

Tsukuba, Ibaraki 305-8571, Japan. Fax: +81-29-853-4323; E-mail: kojima@chem.tsukuba.ac.jp

$\dagger$ Electronic Supplementary Information (ESI) available: Crystal structure of 3, descriptions of hydrogen bonding (1-3) and $\pi-\pi$ interactions (1 and

$50 \mathbf{2}$ ), displacements of atoms in the porphyrin cores, absorption spectra of $\mathbf{1}$ and 2, spectroscopic titration for $\mathbf{1}$ - $\mathbf{3}$ in DMSO, NMR spectral change

for $\mathrm{H}_{2} \mathrm{DPP}$ in the titration with acids in DMSO, fluorescence spectra of $\mathbf{1}$ and 3 in PhCN, absorption spectral change of $\mathrm{H}_{2} \mathrm{DPP}$ in the titration with 2,6-AN- $\left(\mathrm{SO}_{3} \mathrm{H}\right)_{2}$ in PhCN, DPV traces of $\mathrm{H}_{2} \mathrm{DPP}$ with addition of acids, 55 the full list of authors of ref 16. See DOI: $10.1039 / \mathrm{b} 000000 \mathrm{x} /$

¥ Crystal data for 1: monoclinic, $P 2_{1} / a$ (No. 14), $a=15.291(5), b=$ 24.074(9), $c=24.824(9) \AA, \beta=90.017(9)^{\circ}, V=9138(6) \AA^{3}, Z=4, T=$ $123 \mathrm{~K}, R 1=0.105(I>2 \sigma(I)), R w=0.330, \mathrm{GOF}=1.01$. 2: triclinic, $P-1$ (No. 2), $a=16.024(3), b=16.575(3), c=18.866(4) \AA, \alpha=74.873(7), \beta=$ 60 79.655(8), $\gamma=68.318(7)^{\circ}, V=4475.6(16) \AA^{3}, Z=2, T=123 \mathrm{~K}, R 1=$ $0.093(I>2 \sigma(I)), R w=0.299$, GOF $=0.975$. 3: monoclinic, $P 2_{1} / c$ (No. 14), $a=18.383(1), b=20.782(1), c=29.219(1) \AA, \beta=103.722(1), V=$ 10844.1(9) $\AA^{3}, Z=4, T=123 \mathrm{~K}, R 1=0.050(I>2 \sigma(I)), R w=0.130$, GOF $=1.04$. CCDC-727605 (1), 727606 (2), and 727607 (3) contain the 65 supplementary crystallographic data for this paper. Details of crystallography are given in ESI.

1 A. Stone, E. B. Fisher, J. Am. Chem. Soc., 1968, 90, 2735.

2 P. Hambright, in The Porphyrin Handbook, Vol. 3 (Eds: K. M. 70 Kadish, K. M. Smith, R. Guilard), Academic Press, New York, 2000, pp. 129-210.

3 R. I. Walter, E. C. A. Ojadi, H. Linschitz, J. Phys. Chem., 1993, 97, 13308.

4 C. J. Medforth, M. O. Senge, K. M. Smith, L. D. Sparks, J. A. 75 Shelnutt, J. Am. Chem. Soc., 1992, 114, 9859

5 (a) R. Harada, T. Kojima, Chem. Commun., 2005, 716; (b) T. Kojima, T. Nakanishi, R. Harada, K. Ohkubo, S. Yamauchi, S. Fukuzumi, Chem. Eur. J., 2007, 13, 8714; (c) S. Fukuzumi, T. Kojima, J. Mater. Chem., 2008, 18, 1427; (d) T. Nakanishi, T. Kojima, K. Ohkubo, T.

$80 \quad$ Hasobe, K. Nakayama, S. Fukuzumi, Chem. Mater., 2008, 20, 7492; (e) T. Kojima, T. Nakanishi, T. Honda, S. Fukuzumi, J. Porphyrins Phthalocyanines, 2009, 13, 14; $(f)$ T. Nakanishi, K. Ohkubo, T. Kojima, S. Fukuzumi, J. Am. Chem. Soc., 2009, 131, 577.

6 a) T. Kojima, T. Honda, K. Ohkubo, M. Shiro, T. Kusukawa, T. 85 Fukuda, N. Kobayashi, S. Fukuzumi, Angew. Chem. Int. Ed., 2008, 47, 6712; (b) S. Fukuzumi, T. Honda, K. Ohkubo, T. Kojima, Dalton Trans., 2009, 3880.

7 Ö. Almarsson, A. Blaskó, T. C. Bruice, Tetrahedron, 1993, 49, 10239.

908 (a) H. Ogoshi, E. Watanabe, Z. Yoshida, Tetrahedron, 1973, 29, 3241; (b) N. Hirayama, A. Takehara, Y. Sasada, E. Watanabe, H. Ogoshi, Z. Yoshida, J. Chem. Soc., Chem. Commun., 1974, 330; (c) G. De Luca, A. Romeo, L. M. Scolaro, G. Ricciardi, A. Rosa, Inorg. Chem., 2007, 46, 5979.

959 R. Karaman, T. C. Bruice, Inorg. Chem., 1992, 31, 2455.

10 C. P. Hrung, M. Tsutsui, D. L. Culten, E. F. Meyer, Jr., C. N. Morimoto, J. Am. Chem. Soc., 1978, 100, 6068.

11 The $\mathrm{p} K_{\mathrm{a}}$ values of 2-AN-SO${ }_{3} \mathrm{H}$ and 2,6- $\mathrm{AN}-\left(\mathrm{SO}_{3} \mathrm{H}\right)_{2}$ are not available, however, that of benzene sulfonic acid has been known to be 0.70 (in water at $\left.25^{\circ} \mathrm{C}\right)$ : $C R C$ Handbook of Chemistry and Physics, $89^{\text {th }}$ Ed. (Ed.: D. R. Lide), CRC press, Boca Raton, 2008-2009, pp. 8-45. The $\mathrm{p} K_{\mathrm{a}}$ value of 2-AN-COOH has been reported to be 4.18 (in water at $25^{\circ} \mathrm{C}$ ): Lange's Handbook of Chemistry, $15^{\text {th }}$ Ed. (Ed.: J. A. Dean), McGraw-Hill, New York, 1999.

10512 M. F. Acquavella, M. E. Evans, S. W. Farraher, C. J. Névoret, C. J. Abelt, J. Org. Chem., 1994, 59, 2894.

13 For two-step equilibrium: $\left(A-A_{0}\right) /\left(A_{\infty}-A\right)=K_{1}\left(\left[\mathrm{H}^{+}\right]_{0}-\alpha\left[\mathrm{H}_{2} \mathrm{DPP}\right]_{0}\right)$ $\left(\alpha=\left(A-A_{0}\right) /\left(A_{\infty}-A_{0}\right)\right)$, for $K_{1}=\left[\mathrm{H}_{3} \mathrm{DPP}^{+}\right] /\left[\mathrm{H}_{2} \mathrm{DPP}\right]\left[\mathrm{H}^{+}\right]$. Similarly, $K_{2}=\left[\mathrm{H}_{4} \mathrm{DPP}^{2+}\right] /\left[\mathrm{H}_{3} \mathrm{DPP}^{+}\right]\left[\mathrm{H}^{+}\right]$was determined by assuming that the 1 eq addition of the acid gave $\mathrm{H}_{3} \mathrm{DPP}^{+}$quantitatively, where $\left[\mathrm{H}^{+}\right]_{0}=[2-$ AN-SO $\left.{ }_{3} \mathrm{H}\right]$ or $\left[\mathrm{H}^{+}\right]_{0}=2\left[2,6-\mathrm{AN}-\left(\mathrm{SO}_{3} \mathrm{H}\right)_{2}\right]$. For one-step equilibrium: $\left(A-A_{0}\right) /\left(A_{\infty}-A\right)=K\left([2-\mathrm{AN}-\mathrm{COOH}]_{0}-2 \alpha\left[\mathrm{H}_{2} \mathrm{DPP}\right]_{0}\right)^{2}\left(\alpha=\left(A-A_{0}\right) /\right.$ $\left.\left(A_{\infty}-A_{0}\right)\right)$ for $K=\left[\mathrm{H}_{4} \mathrm{DPP}(2-\mathrm{AN}-\mathrm{COO})_{2}\right] /\left[\mathrm{H}_{2} \mathrm{DPP}\right][2-\mathrm{AN}-\mathrm{COOH}]^{2}$.

14 The titration of $\mathrm{H}_{2} \mathrm{DPP}$ with 2,6-AN- $\left(\mathrm{SO}_{3} \mathrm{H}\right)_{2}$ also exhibited 115 saturation behavior by the addition of 0.5 eq of the diacid. See ESI Fig. S9.

15 We could observe a peak at $-0.45 \mathrm{~V}$ due to $\mathrm{H}_{4} \mathrm{DPP}^{2+}$ by the addition

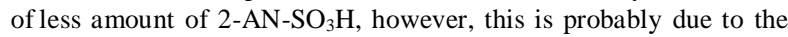
conditions for DPV measurements as represented by the presence of a large amount of $\mathrm{PF}_{6}{ }^{-}$involved as an electrolyte. The presence of a large amount of $\mathrm{PF}_{6}{ }^{-}$anion may induce diprotonation based on hydrogen bond formation as described in ref. 5c. 
16 M. J. Frisch, et al., Gaussian 03, Revision C.02, Gaussian, Inc., Wallingford, CT, 2004 (see ESI for the full list of authors).

\section{Graphical Abstract}

A stable monoprotonated porphyrin (porphyrin monoacid) was obtained by reaction of saddle-distorted dodeca-phenylporphyrin with anthracene sulfonic acids and crystal structures of its supramolecular assemblies were determined.

10



